\title{
HETEROSE SOBRE OS PESOS DE BOVINOS CANCHIM E ABERDEEN ANGUS E DE SEUS CRUZAMENTOS RECÍPROCOS ${ }^{1}$
}

\author{
DANIEL PEROTTO ${ }^{2}$, ANTONIO CARLOS CUBAS ${ }^{3}$, JOSÉ LUIZ MOLETTA ${ }^{4}$ e CARLOS LESSKIU ${ }^{5}$
}

\begin{abstract}
RESUMO - O trabalho foi conduzido para estimar a heterose sobre os pesos ao nascimento (PNT), à desmama (P210) e ao ano (P365) e sobre os ganhos de pesos médios diários do nascimento à desmama (G210) e da desmama ao ano (G365) nas quatro primeiras gerações do sistema de cruzamentos alternados entre as raças Canchim (C) e Aberdeen Angus (A). Os dados de 1.147 bezerros nascidos de 1981 a 1998 foram analisados pelo método dos mínimos quadrados, ajustando-se um modelo linear que incluiu os efeitos linear e quadrático da idade da mãe do bezerro e os efeitos fixos de sexo, grupo genético, mês e ano de nascimento do bezerro. Estimativas de heterose e de outras diferenças genéticas foram estimadas por contrastes entre médias e testadas pelo teste t. O contraste " $\mathrm{C}-\mathrm{A}$ " foi positivo e significativo $(\mathrm{P}<0,001)$ para as cinco características. $\mathrm{O}$ contraste $\mathrm{F}_{1} \mathrm{CA}-\mathrm{F}_{1} \mathrm{AC}$ teve sinal negativo e foi altamente significativo $(\mathrm{P}<0,001)$ para $\mathrm{P} 210$ e $\mathrm{G} 210$ e significativo $(\mathrm{P}<0,05)$ para $\mathrm{P} 365$. A geração $F_{1}$ exibiu heterose de 4,8\% para P210 e de 4,9\% para G210. A heterose materna foi de 3,7\%, $5,8 \%, 6,3 \%$ e 20,4\%, respectivamente, para P210, G210, P365 e G365. A heterose média das terceira e quarta gerações do cruzamento alternado entre C e A foi de 4,6\% para P210, 5,3\% para G210 e de $3,5 \%$ para $\mathrm{P} 365$.
\end{abstract}

Termos para indexação: gado de corte, cruzamentos alternados, diferenças genéticas.

\section{HETEROSIS UPON WEIGHTS IN CANCHIM AND ABERDEEN ANGUS CALVES AND IN THEIR RECIPROCAL CROSSES}

\begin{abstract}
The study was conducted to estimate heterosis upon birth weight (PNT), weaning weight (P210), yearling weight (P365) and daily weight gain from birth to weaning (G210) and from weaning to one year of age (G365) in the first, second, third and fourth generations of a rotational crossbreeding system between Canchim (C) and Aberdeen Angus (A). Data from 1,147 calves born from 1981 to 1998 were analyzed by least squares procedures fitting a linear model that included the linear and the quadratic effects of age of the dam of the calf plus the fixed effects of sex, genetic group, month and year of birth of calf. Estimates of heterosis and of other genetic differences were obtained by linear contrasts of appropriate means and tested by the $t$ test. The contrast $\mathrm{C}$-A was positive and significant $(\mathrm{P}<0.001)$ for all five traits. The contrast $\mathrm{F}_{1} \mathrm{CA}-\mathrm{F}_{1} \mathrm{AC}$ was negative and highly significant $(\mathrm{P}<0.001)$ for $\mathrm{P} 210$ and for $\mathrm{G} 210$ and significant $(\mathrm{P}<0.05)$ for $\mathrm{P} 365$. The $\mathrm{F}_{1}$ generation exhibited heterosis of $4.8 \%$ for P210 and of $4.9 \%$ for G210. Maternal heterosis was 3.7\%, 5.8\%, 6.3\% and $20.4 \%$, respectively, for P210, G210, P365 and G365. The heterosis estimated for the mean of the third and fourth generations of the rotational crossbreeding system between $\mathrm{C}$ and A was $4.6 \%$ for P210, 5.3\% for $\mathrm{G} 210$ and 3.5\% for P365.
\end{abstract}

Index terms: beef cattle, rotational crossbreeding, genetic differences.

${ }^{1}$ Aceito para publicação em 25 de agosto de 2000.

${ }^{2}$ Eng. Agrôn., Ph.D., Instituto Agronômico do Paraná (IAPAR), Pólo Regional de Pesquisa de Curitiba, Caixa Postal 2031, CEP 80011-970 Curitiba, PR. E-mail: dperotto@pr.gov.br

${ }^{3}$ Méd. Vet., Ph.D., Prof. Adjunto, Faculdade de Agronomia, Universidade Federal do Mato Grosso do Sul, Caixa Postal 533, CEP 79804-970 Dourados, MS. E-mail: acubas@ceud.ufms.br

${ }^{4}$ Zootec., M.Sc., IAPAR, Estação Experimental Fazenda Modelo, Caixa Postal 129, CEP 84001-970 Ponta Grossa, PR. E-mail: moletta@pr.gov.br

${ }^{5}$ Méd. Vet., M.Sc., IAPAR, Estação Experimental Fazenda Modelo. E-mail: efmiapar@pr.gov.br

\section{INTRODUÇÃO}

A implementação de esquemas sistemáticos de cruzamentos, com os objetivos de explorar as diferenças genéticas entre as raças, os efeitos da heterose e da complementaridade e de flexibilizar os sistemas de produção, constitui uma das três estratégias, não mutuamente exclusivas, disponíveis para utilizar recursos genéticos na produção de carne bovina (Barbosa \& Alencar, 1995). Segundo os mesmos autores, 
embora seja possível transferir resultados e recomendações de pesquisa gerados em países desenvolvidos para aqueles em desenvolvimento, como o Brasil, aspectos fundamentais como a caracterização biológica das raças e dos cruzamentos e a avaliação econômica de sistemas de cruzamentos devem ser pesquisados em diferentes sistemas de produção para que as diferenças raciais, a heterose e a complementaridade possam ser exploradas de maneira adequada e efetiva.

Os trabalhos de pesquisa em cruzamentos de bovinos de corte no Brasil têm enfatizado a caracterização biológica de raças e de cruzamentos para características de relevância econômica (Becker, 1985; Razook et al., 1986; Euclides Filho et al., 1996; Perotto et al., 1996). Sintetizando os resultados de estudos de cruzamentos conduzidos no Brasil de 1934 a 1994, Barbosa \& Alencar (1995) encontraram melhor desempenho dos mestiços europeu x zebu em relação aos zebuínos puros quanto a características como velocidade de crescimento $(15 \%)$, eficiência reprodutiva $(43 \%)$ e mérito da carcaça $(0,7 \%)$. Só mais recentemente foram publicadas pesquisas apresentando estimativas de heterose com relação a características de importância econômica na produção de carne bovina (Alves Filho \& Restle, 1997; Perotto et al., 1998; Trematore et al., 1998; Perotto et al., 1999; Wolf et al., 1999). Segundo resultados de Alves Filho \& Restle (1997), mestiços recíprocos 3/4 Charolês + 1/4 Nelore e 3/4 Nelore + 1/4 Charolês apresentaram respostas heteróticas de 10,34\%, $23,38 \%$ e $29,87 \%$, respectivamente para os pesos ao nascimento, à desmama (aos 90 dias) e para o ganho do nascimento à desmama. Os autores concluíram que bezerros filhos de vacas $F_{1}$ Charolês x Nelore tiveram melhor desempenho que os gerados por vacas puras nas mesmas condições de criação.

Analisando dados de crescimento até a desmama (aos 208 dias, em média) de bezerros Charolês, Caracu e seus mestiços recíprocos gerados por um esquema de cruzamentos alternados entre as duas raças, Perotto et al. (1998) encontraram estimativas de heterose na geração $\mathrm{F}_{1}$ da ordem de $5,1 \%, 4,6 \%$ e $6,7 \%$, respectivamente para os pesos ao nascimento e à desmama e para o ganho de peso do nascimento à desmama. No mesmo trabalho, os autores verificaram níveis de heterose de 7,0\%, 7,0\% e 5,8\%, para as mesmas característica, para a média das gerações dos 3/4 e 5/8 recíprocos.

Em outro trabalho, Perotto et al. (1999) estudaram os efeitos da heterozigose, com respeito à raça de origem dos genes, sobre pesos ao nascimento, à desmama (aos 205 dias) e aos 12 meses de idade e sobre os ganhos do nascimento à desmama e da desmama aos 12 meses em bezerros Nelore e em mestiços Red Angus x Nelore, encontrando efeitos positivos e significativos das heterozigoses individual e materna sobre os pesos à desmama e aos 12 meses, bem como sobre os ganhos do nascimento à desmama e da desmama aos 12 meses. Os autores estimaram que as diferenças entre os $F_{1}$ Red Angus x Nelore e os Nelore puros foram da ordem de $16 \%, 20 \%, 22 \%$ e $50 \%$, respectivamente para o peso à desmama, ganho do nascimento à desmama, peso aos 12 meses e ganho da desmama aos 12 meses.

Wolf et al. (1999) estimaram os efeitos das heterozigoses individual e materna sobre o ganho de peso do nascimento à desmama em bezerros Pampeano-Braford (cruzamento de Nelore x Hereford). Os resultados mostraram que a heterose total incrementou a média de ganho de peso pré-desmame em $15,99 \%$, revelando que os bezerros $F_{1}$ Nelore x Hereford tiveram 9,06\% de seu ganho de peso por causa da heterozigose individual, e que as vacas $F_{1}$ Nelore $x$ Hereford foram responsáveis por $20 \%$ dos ganhos de seus produtos.

Efeitos heterozigóticos individuais e maternos positivos e significativos foram reportados também por Trematore et al. (1998) para os pesos ao nascimento e à desmama (ajustado para 270 dias de idade) e para o ganho de peso do nascimento à desmama em bezerros oriundos de cruzamentos Charolês x Nelore. Esses autores estimaram valores de heterose total correspondentes a $5,13 \%$ para o peso ao nascimento, $8,69 \%$ para o peso à desmama e $8,18 \%$ para o ganho de peso do nascimento à desmama.

O presente trabalho é parte de um projeto que objetiva avaliar o cruzamento alternado entre as raças Canchim e Aberdeen Angus para produção de carne bovina na região centro-sul do Estado do Paraná. Os objetivos específicos deste estudo foram estimar a heterose sobre os pesos ao nascimento, à desmama e aos 12 meses e sobre os ganhos de peso 
do nascimento à desmama e da desmama aos 12 meses nas sucessivas gerações de mestiços recíprocos oriundos do referido esquema de cruzamentos.

\section{MATERIAL E MÉTODOS}

Os dados usados no presente estudo foram coletados na Estação Experimental Fazenda Modelo, em Ponta Grossa, Paraná, localizada a $25^{\circ} 6^{\prime}$ de latitude Sul e a $50^{\circ} 9^{\prime}$ de longitude Oeste. A altitude é de $783 \mathrm{~m}$ e as médias anuais de temperatura e precipitação pluvial são, respectivamente, $18^{\circ} \mathrm{C}$ e $1.402 \mathrm{~mm}$. A região se insere nos Campos Gerais, que se estendem desde a fronteira com o Estado de Santa Catarina até os limites com o Estado de São Paulo. Nesses campos, predomina uma grande diversidade de gramíneas, destacando-se espécies de Traquipogon, Andropogon, Paspalum, Aristida, Panicum e Eragrostis. Entre as gramíneas, vegetam ervas, semi-arbustos e arbustos pertencentes às famílias das compostas, leguminosas, malváceas e rubiáceas (Maack, 1968). Atualmente, a tendência é de substituição da estepe natural por pastagens cultivadas de Hemarthria altissima, Paspalun notatum e Tifton (Cynodon sp.). A criação de gado de corte é atividade econômica nessa região há mais de 200 anos.

O trabalho que gerou os dados utilizados neste estudo foi iniciado em 1980, com os objetivos de caracterizar biologicamente as raças Canchim (C) e Aberdeen Angus (A) quanto às principais características que interferem na produção de carne bovina, avaliar o esquema de cruzamentos alternados Aberdeen Angus x Canchim para produção de carne na região centro-sul do Estado do Paraná e estimar a heterose retida nas gerações avançadas do cruzamento alternado com relação às características importantes em gado de corte.

O rebanho Canchim já existia na Estação Experimental Fazenda Modelo quando esta foi transferida da Embrapa para o IAPAR em 1979. Ao longo dos anos, o Canchim da Fazenda Modelo, que era originário da Estação do Ministério da Agricultura de São Carlos, SP, onde a raça foi formada, recebeu migrações de germoplasma de rebanhos de Lucélia, SP, Guarapuava, PR e Ponta Grossa, PR. Atualmente, o Canchim da Fazenda Modelo está sendo multiplicado com sêmen disponibilizado pela Associação Brasileira de Criadores de Canchim. Animais Aberdeen Angus foram adquiridos inicialmente na região de Ponta Grossa, PR, e em Júlio de Castilhos, RS. Mais tarde, o plantel Aberdeen Angus foi melhorado através de animais adquiridos da Estância São Bibiano, de Uruguaina, RS. Hoje, o rebanho Aberdeen Angus está sendo reproduzido com sêmen de touros estrangeiros com resultados de teste de progênie conhecidos.
O delineamento experimental contemplou quatro planos de acasalamentos, a saber: touro $\mathrm{C} \mathrm{x}$ vaca $\mathrm{C}$, touro $\mathrm{C} \mathrm{x}$ vaca $\mathrm{A}$, touro $\mathrm{A} \mathrm{x}$ vaca $\mathrm{C}$ e touro $\mathrm{A} \mathrm{x}$ vaca $\mathrm{A}$. O número de vacas por plano de acasalamento por ano foi de aproximadamente 25 . O sistema alternado de cruzamentos entre $\mathrm{C}$ e A foi implementado ao longo do tempo pelos seguintes acasalamentos: touro $\mathrm{C} x$ vaca $\mathrm{F}_{1}(1 / 2 \mathrm{~A}+1 / 2 \mathrm{C})$; touro $\mathrm{A} x$ vaca $\mathrm{F}_{1}(1 / 2 \mathrm{C}+1 / 2 \mathrm{~A})$; touro $\mathrm{C} x$ vaca $3 / 4 \mathrm{~A}+1 / 4 \mathrm{C}$; touro $\mathrm{A} x$ vaca $3 / 4 \mathrm{C}+1 / 4 \mathrm{~A}$; touro $\mathrm{C} x$ vaca $5 / 8 \mathrm{~A}+3 / 8 \mathrm{C}$; touro A x vaca $5 / 8 \mathrm{C}+3 / 8 \mathrm{~A}$, e assim sucessivamente. À medida que as fêmeas das gerações mais avançadas do cruzamento alternado tornavam-se disponíveis para a reprodução, fêmeas puras ou mestiças de gerações anteriores foram sendo descartadas, para manter fixo o número de fêmeas por plano de acasalamento por ano. Os mesmos touros Canchim que produziram os animais puros dessa raça também foram usados para produzir os mestiços $\mathrm{C} \times \mathrm{A}$. Igualmente, os touros Aberdeen Angus produziram animais A e mestiços A x C. Até 1998, o experimento produziu o total de 1.147 animais conforme indicado na Tabela 1.

Nos anos iniciais do projeto, as vacas de cria eram mantidas exclusivamente em pastagens nativas, mas no inverno tinham acesso a pastagens anuais da mistura aveia (Avena sativa) + azevém (Lolium multiflorum), pelo período de duas horas por dia, aproximadamente. A partir de 1989, foram introduzidas, na Estação Experimental Fazenda Modelo, pastagens cultivadas de Hemarthria altissima, e o rebanho de cria passou a ser mantido nessas pastagens, principalmente no período entre o final do verão e o início da primavera (março a setembro), permanecendo o restante do tempo (outubro a fevereiro) em campo nativo. $\mathrm{O}$ acesso às pastagens de aveia e de azevém no inverno continuou por todo o período experimental, na forma acima descrita. No período pré-parto, as vacas gestantes eram transferidas a um piquete-maternidade, onde recebiam suplementação alimentar à base de silagem de milho ( $15 \mathrm{~kg} /$ cabeça/dia) e concentrado $(4 \mathrm{~kg} /$ cabeça/dia). Este concentrado era composto por $46 \%$ de rolão de milho, $28 \%$ de milho em grão moído, $25 \%$ de soja moída e $1 \%$ de sal mineralizado. Até 1992, as coberturas ocorriam no campo, numa estação de monta de 15 de setembro a 31 de dezembro, procurando-se manter a relação touro:vaca de 1:17, ou seja, três touros para 50 vacas. A partir de 1993, passou-se a usar a inseminação artificial, com o mínimo de cinco touros de cada raça por ano. Os nascimentos ocorriam de junho a outubro, e os desmames eram feitos em março. O manejo alimentar dos bezerros durante o período compreendido entre o desmame e os 12 meses de idade também sofreu alterações com o passar do tempo. Nos quatro primeiros anos do trabalho, os bezerros des- 
mamados eram transferidos diretamente ao campo nativo onde permaneciam até o início do inverno, quando passavam a ter acesso limitado (duas horas por dia) a pastos de aveia + azevém. De 1985 a 1987, logo que desmamados, os bezerros permaneciam em pastos de capim-elefante (Pennisetum purpureum) por aproximadamente dois meses, sendo depois transferidos para pastagens nativas com suplementação invernal pelo pastejo em pastos de aveia + azevém, pelo período de duas horas por dia. A partir de 1988, o manejo dos bezerros foi igual ao dos anos anteriores, porém os pastos nativos foram sendo substituídos por pastagens de Hemarthria altissima. Finalmente, desde 1996, os bezerros foram desmamados precocemente aos 90 dias de idade, quando passaram a receber $2 \mathrm{~kg}$ por animal por dia de concentrado formulado para conter $15 \%$ de proteína bruta e $73 \%$ de nutrientes digestíveis totais, até o fim do inverno.

Para efeito das análises estatísticas, o conjunto de dados de cada característica (PNT, peso ao nascimento, registrado no decorrer das primeiras 24 horas de vida; P210, peso à desmama, corrigido para a idade de 210 dias; G210, ganho de peso médio diário do nascimento aos 210 dias, P365, peso aos 12 meses, corrigido para a idade de 365 dias; e G365, ganho de peso médio diário dos 210 aos 365 dias) foi subdividido em quatro subconjuntos a saber: subconjunto I (período 1981/88) - englobou dados dos grupos $\mathrm{C}, \mathrm{A}, \mathrm{F}_{1} \mathrm{CA}(1 / 2 \mathrm{C}+1 / 2 \mathrm{~A})$ e $\mathrm{F}_{1} \mathrm{AC}(1 / 2 \mathrm{~A}+$ $1 / 2 \mathrm{C})$;

subconjunto II (período 1985/89) - englobou dados dos grupos $\mathrm{C}, \mathrm{A}, \mathrm{F}_{1} \mathrm{CA}, \mathrm{F}_{1} \mathrm{AC}, 3 / 4 \mathrm{C}+1 / 4 \mathrm{~A}$ e $3 / 4 \mathrm{~A}+$ $1 / 4 \mathrm{C}$;

subconjunto III (período 1990/93) - englobou dados dos grupos $\mathrm{C}, \mathrm{A}, 3 / 4 \mathrm{C}+1 / 4 \mathrm{~A}, 3 / 4 \mathrm{~A}+1 / 4 \mathrm{C}, 5 / 8 \mathrm{C}+3 / 8 \mathrm{~A} \mathrm{e}$ $5 / 8 \mathrm{~A}+3 / 8 \mathrm{C}$;

subconjunto IV (período 1994/98) - englobou dados dos grupos $\mathrm{C}, \mathrm{A}, 5 / 8 \mathrm{C}+3 / 8 \mathrm{~A}, 5 / 8 \mathrm{~A}+3 / 8 \mathrm{C}, 11 / 16 \mathrm{C}+$ $5 / 16 \mathrm{~A}$ e $11 / 16 \mathrm{~A}+5 / 16 \mathrm{C}$.

As correções dos pesos à desmama para a idade de 210 dias e do peso ao ano para idade de 365 dias foram feitas com o emprego dos coeficientes de regressão linear dos pesos sobre a idade, estimados separadamente por grupo genético e sexo. Os ganhos médios diários do nascimento à desmama e da desmama ao ano foram calculados a partir dos pesos corrigidos. Cada característica foi analisada pelo método dos quadrados mínimos (SAS Institute, 1994), ajustando-se o modelo linear seguinte:

$\mathrm{Y}_{\mathrm{ijklm}}=\mu+\mathrm{b}_{1} \mathrm{IM}+\mathrm{b}_{2} \mathrm{IM}^{2}+\mathrm{G}_{\mathrm{i}}+\mathrm{S}_{\mathrm{j}}+\mathrm{M}_{\mathrm{k}}+\mathrm{A}_{1}+\varepsilon_{\mathrm{ijklm}}$ em que:

$\mathrm{Y}_{\mathrm{ijklm}}$ é o valor da característica (PNT, P210, G210, P365 e G365) no indivíduo; $\mu$ é a média geral da característica;

TABELA 1. Distribuição dos animais segundo o ano de nascimento e o grupo genético.

\begin{tabular}{|c|c|c|c|c|c|c|c|c|c|c|}
\hline \multirow[t]{2}{*}{ Ano } & \multicolumn{10}{|c|}{ Grupo genético $^{1}$} \\
\hline & $\mathrm{C}$ & $1 \mathrm{C} 1 \mathrm{~A}$ & $3 \mathrm{C} 1 \mathrm{~A}$ & $5 \mathrm{C} 3 \mathrm{~A}$ & $11 \mathrm{C} 5 \mathrm{~A}$ & $11 \mathrm{~A} 5 \mathrm{C}$ & $5 \mathrm{~A} 3 \mathrm{C}$ & $3 \mathrm{~A} 1 \mathrm{C}$ & $1 \mathrm{~A} 1 \mathrm{C}$ & A \\
\hline 1981 & 3 & 13 & & & & & & & 10 & 1 \\
\hline 1982 & 3 & 17 & & & & & & & 13 & 14 \\
\hline 1983 & 3 & 5 & & & & & & & 12 & \\
\hline 1984 & 4 & 10 & & & & & & & 7 & 4 \\
\hline 1985 & 6 & 13 & & & & & & 5 & 13 & 11 \\
\hline 1986 & 8 & 4 & 11 & & & & & 11 & 8 & 19 \\
\hline 1987 & 7 & 4 & 12 & & & & & 11 & 5 & 14 \\
\hline 1988 & 2 & 6 & 16 & & & & & 10 & 1 & 15 \\
\hline 1989 & 13 & & 24 & 1 & & & 1 & 21 & 1 & 23 \\
\hline 1990 & 10 & 1 & 20 & 3 & & & 5 & 15 & & 21 \\
\hline 1991 & 16 & & 19 & 8 & & & 5 & 10 & & 21 \\
\hline 1992 & 20 & 7 & 16 & 14 & & & 11 & 10 & & 19 \\
\hline 1993 & 13 & 2 & 9 & 15 & 1 & & 9 & 4 & & 8 \\
\hline 1994 & 19 & 5 & 5 & 14 & & 3 & 8 & & & 19 \\
\hline 1995 & 20 & 5 & 5 & 15 & 7 & 2 & 11 & & 3 & 11 \\
\hline 1996 & 17 & 4 & 1 & 15 & 9 & 8 & 15 & & 1 & 24 \\
\hline 1997 & 11 & 9 & & 5 & 4 & 4 & 5 & & 9 & 9 \\
\hline 1998 & 30 & 15 & 1 & & 5 & 5 & 7 & & 13 & 15 \\
\hline Total & 217 & 120 & 139 & 90 & 26 & 22 & 79 & 97 & 96 & 261 \\
\hline
\end{tabular}


$\mathrm{b}_{1}$ e $\mathrm{b}_{2}$ são coeficientes de regressão parcial; IM e IM ${ }^{2}$ representam a idade da mãe, em dias, e a idade da mãe ao quadrado, respectivamente; $\mathrm{G}_{\mathrm{i}}$ é o efeito fixo do grupo genético do bezerro; $S_{j}$ é o efeito fixo do sexo do bezerro; $\mathrm{M}_{\mathrm{k}}$ é o efeito fixo do mês de nascimento do bezerro; $\mathrm{A}_{1}$ é o efeito fixo do ano de nascimento do bezerro; e, $\varepsilon_{\mathrm{ijklm}}$ é o erro aleatório associado a cada valor de $\mathrm{Y}$.

Os efeitos das interações GxA e GxS não foram incluídos nos modelos finais de análise porque verificou-se que não eram significativos. Estimativas da diferença entre as duas raças (C-A), da diferença recíproca (CA-AC) e da heterose (média dos mestiços - média das raças paternas) exibida em cada geração do cruzamento alternado foram calculadas por meio de contrastes entre as médias dos grupos genéticos pertinentes a cada caso. A significância estatística dos contrastes entre médias foi verificada pelo teste da hipótese nula (valor do contraste igual a zero) computando-se estatísticas t e comparando-as com valores tabulados das apropriadas distribuições t. Os valores esperados de cada contraste foram deduzidos postulando-se o seguinte modelo genético de desempenho:

$Y_{i j}=\mu+a_{A}{ }^{I} f_{i}+a_{A}{ }^{M} f_{i}^{*}+h_{A C}{ }^{I} f_{i j}+h_{A C}{ }^{M} f_{i j}{ }^{*}+\varepsilon_{i j}$ em que:

$Y_{\mathrm{ij}}$ é o valor do desempenho do grupo genético resultante da combinação entre a i-ésima proporção de genes Aberdeen Angus e a j-ésima proporção de genes Canchim; $\mu$ é a média de desempenho de todos os grupos genéticos formados pela combinação Aberdeen Angus x Canchim em diferentes proporções; $a_{A}{ }^{I}$ é o efeito genético aditivo da raça Aberdeen Angus expresso como desvio a partir do efeito genético aditivo da raça Canchim $\left(\mathrm{a}_{C} \mathrm{I}\right) ; \mathrm{f}_{\mathrm{i}}$ é a fração esperada de genes Aberdeen Angus no genótipo do bezerro; $a_{A}{ }^{\mathrm{M}}$ é o efeito genético aditivo materno da raça Aberdeen Angus expresso como desvio a partir do efeito genético aditivo materno da raça Canchim $\left(\mathrm{a}_{\mathrm{C}}{ }^{\mathrm{M}}\right) ; \mathrm{f}_{\mathrm{i}}{ }^{*}$ é a fração esperada de genes Aberdeen Angus no genótipo da mãe do bezerro; $\mathrm{h}_{\mathrm{AC}} \mathrm{I}$ é o efeito da heterozigose individu$\mathrm{al}$; $\mathrm{f}_{\mathrm{ij}}$ é a fração esperada de locos heterozigotos, com respeito à raça de origem dos genes, no genótipo do bezerro; $\mathrm{h}_{\mathrm{AC}}{ }^{\mathrm{M}}$ é o efeito da heterozigose materna; $\mathrm{f}_{\mathrm{ij}}{ }^{*}$ é a fração esperada de locos heterozigotos, com respeito à raça de origem dos genes, no genótipo da mãe do bezerro; e $\varepsilon_{\mathrm{ij}}$ é o erro aleatório associado ao valor de cada $\mathrm{Y}_{\mathrm{ij}}$. No presente caso, $\mathrm{e}_{\mathrm{ij}}$ pode resultar de segregação mendeliana, ligação gênica, efeitos epistáticos, efeitos ligados ao sexo e efeitos genéticos paternos. Estatisticamente, $\mathrm{a}_{\mathrm{A}}^{\mathrm{I}}, \mathrm{a}_{\mathrm{A}}^{\mathrm{M}}, \mathrm{h}_{\mathrm{AC}} \mathrm{I}^{\mathrm{I}} \mathrm{e}$ $\mathrm{h}_{\mathrm{AC}}{ }^{\mathrm{M}}$ podem ser computados como coeficientes de regressão parcial da variável dependente sobre $\mathrm{f}_{\mathrm{i}}, \mathrm{f}_{\mathrm{i}}{ }^{*}, \mathrm{f}_{\mathrm{ij}} \mathrm{e}_{\mathrm{ij}}{ }^{*}$, respectivamente. Os valores esperados de $f_{i}, f_{i}^{*}, f_{i j}$ e $f_{i j}^{*}$, nos grupos genéticos presentes nos dados aqui analisados, são fornecidos na Tabela 2. As análises estatísticas foram realizadas utilizando-se o procedimento GLM do Programa SAS (SAS Institute, 1994).

\section{RESULTADOS E DISCUSSÃO}

Os coeficientes de determinação estatística gerados pelas análises variaram de 0,20 a 0,24 para PNT; de 0,62 a 0,94 para P210; de 0,47 a 0,72 para G210; de 0,25 a 0,83 para P365, e de 0,25 a 0,60 para G365. À exceção do PNT, os valores baixos sempre estiveram associados a períodos em que a característica sob análise apresentou alto coeficiente de variação.

Os efeitos linear (IM) e quadrático $\left(\mathrm{IM}^{2}\right)$ da idade da mãe foram mantidos nos modelos de análise de PNT, P210 e G210, porque em alguns casos se aproximaram do nível de significância de 5\%. $\mathrm{O}$ grupo genético do bezerro só não teve efeito significativo (P>0,05) para G365 no período 1985/89. O sexo do bezerro não influenciou qualquer das características em qualquer dos períodos considerados.

O PNT teve efeito do mês de nascimento do bezerro no período 1994/98 enquanto P365 e G365 não acusaram influência desse fator no período 1981/88.

Todas as características, exceto PNT, foram influenciadas $(\mathrm{P}<0,05$ a $\mathrm{P}<0,001)$ pelo ano de nasci-

TABELA 2. Valores esperados das frações dos efeitos genéticos considerados no modelo genético de desempenho, segundo o genótipo do animal.

\begin{tabular}{lcccc}
\hline \multirow{2}{*}{ Grupo genético } & \multicolumn{4}{c}{ Fração esperada do efeito genético ${ }^{1}$} \\
\cline { 2 - 5 } & $\mathrm{f}_{\mathrm{i}}$ & $\mathrm{f}_{\mathrm{i}}{ }^{*}$ & $\mathrm{f}_{\mathrm{ij}}$ & $\mathrm{f}_{\mathrm{ij}}{ }^{*}$ \\
\hline Canchim (C) & 0,0000 & 0,0000 & 0,0000 & 0,0000 \\
Aberdeen Angus (A) & 1,0000 & 1,0000 & 0,0000 & 0,0000 \\
$1 / 2 \mathrm{C}+1 / 2 \mathrm{~A}$ & 0,5000 & 1,0000 & 1,0000 & 0,0000 \\
$1 / 2 \mathrm{~A}+1 / 2 \mathrm{C}$ & 0,5000 & 0,0000 & 1,0000 & 0,0000 \\
$3 / 4 \mathrm{C}+1 / 4 \mathrm{~A}$ & 0,2500 & 0,5000 & 0,5000 & 1,0000 \\
$3 / 4 \mathrm{~A}+1 / 4 \mathrm{C}$ & 0,7500 & 0,5000 & 0,5000 & 1,0000 \\
$5 / 8 \mathrm{C}+3 / 8 \mathrm{~A}$ & 0,3750 & 0,7500 & 0,7500 & 0,5000 \\
$5 / 8 \mathrm{~A}+3 / 8 \mathrm{C}$ & 0,6250 & 0,2500 & 0,7500 & 0,5000 \\
$11 / 16 \mathrm{C}+5 / 16 \mathrm{~A}$ & 0,3125 & 0,6250 & 0,6250 & 0,7500 \\
$11 / 16 \mathrm{~A}+5 / 16 \mathrm{C}$ & 0,6875 & 0,3750 & 0,6250 & 0,7500 \\
\hline
\end{tabular}

${ }^{1} \mathrm{f}_{\mathrm{i}}$ : fração esperada de genes Aberdeen Angus no genótipo do bezerro; $\mathrm{f}_{\mathrm{i}}^{*}$ : fração esperada de genes Aberdeen Angus no genótipo da mãe do bezerro; $\mathrm{f}_{\mathrm{ij}}$ : fração esperada de locos com um gene Aberdeen Angus e outro gene Canchim no genótipo do bezerro; $\mathrm{f}_{\mathrm{ij}}{ }^{*}$ : fração esperada de locos com um gene Aberdeen Angus e outro gene Canchim no genótipo da mãe do bezerro. 
mento do bezerro nos períodos 1981/88 e 1985/89. A partir de 1990, o ano só teve efeito $(\mathrm{P}<0,001)$ sobre P210 no período 1990/93.

A Tabela 3 apresenta, para as cinco características, as médias ponderadas das médias ajustadas dos grupos em cada subconjunto de análise em que o grupo esteve representado. A média do PNT de $33,6 \mathrm{~kg}$ para o Canchim está próxima dos 34,77 kg (Alencar et al., 1998), mas é inferior à média da raça de $36 \mathrm{~kg}$ (Barbosa \& Duarte, 1989). Já a média de 29,4 kg do Aberdeen Angus é compatível com o valor de 28,2 kg (Chapman et al., 1973) para bezerros dessa raça em condições subtropicais.

As médias para P210 variaram de $144,5 \mathrm{~kg}$ a $172,6 \mathrm{~kg}$. As médias dos grupos 11/16 recíprocos referem-se ao período 1994/98, no qual os valores correspondentes aos grupos $\mathrm{Ce} \mathrm{A}$ foram, respectivamente, $149 \mathrm{~kg}$ e $138 \mathrm{~kg}$. Esses baixos valores devemse ao fato de que, a partir de 1996, os bezerros foram desmamados aos 90 dias de idade. Para os demais períodos, as médias de P210 variaram de $148 \mathrm{~kg}$ a $175 \mathrm{~kg}$, sendo compatíveis com as condições ambientais em que os animais foram mantidos.

TABELA 3. Médias dos pesos ao nascimento (PNT), à desmama corrigido para 210 dias $(\mathrm{P} 210) \mathrm{e}$ ao ano corrigido para 365 dias (P365), e dos ganhos de peso médios diários do nascimento aos 210 dias (G210) e dos 210 aos 365 dias (G365) em bovinos Canchim, Aberdeen Angus e em mestiços gerados pelo cruzamento alternado entre essas duas raças.

\begin{tabular}{lccccc}
\hline Grupo genético & \multicolumn{5}{c}{ Característica } \\
\cline { 2 - 6 } & $\begin{array}{r}\text { PNT } \\
(\mathrm{kg})\end{array}$ & $\begin{array}{r}\text { P210 } \\
(\mathrm{kg})\end{array}$ & $\begin{array}{c}\text { G210 } \\
(\mathrm{g})\end{array}$ & $\begin{array}{r}\text { P365 } \\
(\mathrm{kg})\end{array}$ & $\begin{array}{c}\text { G365 } \\
(\mathrm{g})\end{array}$ \\
\hline Canchim (C) & 33,6 & 158,2 & 587 & 189,0 & 191 \\
Aberdeen Angus (A) & 29,4 & 148,0 & 556 & 168,0 & 123 \\
1/2C+1/2A & 32,1 & 156,4 & 578 & 168,8 & 92 \\
1/2A+1/2C & 30,5 & 172,6 & 664 & 176,6 & 27 \\
3/4C+1/4A & 32,4 & 168,9 & 627 & 190,7 & 139 \\
3/4A+1/4C & 28,8 & 162,9 & 620 & 185,1 & 143 \\
5/8C+3/8A & 32,7 & 161,0 & 611 & 188,1 & 180 \\
5/8A+3/8C & 31,1 & 156,4 & 592 & 192,6 & 228 \\
11/16C + 5/16A & 35,3 & 146,3 & 528 & 195,9 & 335 \\
11/16A + 5/16C & 34,8 & 144,5 & 523 & 170,5 & 172 \\
\hline
\end{tabular}

A média geral de $627 \mathrm{~g} /$ dia para G210 no período 1981/93 é comparável com os resultados de Postiglioni \& Picanço (1979) com relação ao desempenho animal no campo nativo. No período 1994/98, a média geral para G210 foi 556 g/dia, indicando que a substituição da amamentação natural pelo fornecimento de concentrado não proporcionou um bom desempenho dos bezerros. Em geral, as médias de peso aos 210 dias no presente estudo comparam-se aos valores da literatura. Becker (1985) encontrou média de peso aos 205 dias de $160 \mathrm{~kg}$ para machos Hereford em pasto nativo, mais suplementação no inverno. No mesmo trabalho, bezerros trimestiços filhos de touro Angus tiveram desempenho igual aos Hereford. Segundo Barbosa \& Duarte (1989), as médias de peso à desmama de bezerros Canchim variaram de $166 \mathrm{~kg}$ aos 180 dias a $211 \mathrm{~kg}$ aos 270 dias.

As médias para G365 foram registradas no outono-inverno e também refletem as condições ambientais do experimento. As médias gerais para G365 foram 66 g/dia, 104 g/dia, 206 g/dia e 218 g/dia, respectivamente, para os períodos 1981/88, 1985/89, $1990 / 93$ e 1994/98. Os pesos ao ano variaram com o grupo genético de $168 \mathrm{~kg}$ a $196 \mathrm{~kg}$. A literatura registra médias de peso aos 12 meses de $164 \mathrm{~kg}$ e de $224 \mathrm{~kg}$, respectivamente, para fêmeas e machos Canchim (Alencar et al., 1987).

As estimativas do contraste C-A para PNT variaram de $3,3 \pm 0,9 \mathrm{~kg}$ a $5,1 \pm 0,8 \mathrm{~kg}(\mathrm{P}<0,001)$, indicando que, em média, os bezerros $C$ nascem $4,2 \mathrm{~kg}$ mais pesados que os bezerros A. Por outro lado, os contrastes CA-AC e $\mathrm{F}_{1}-\overline{\mathrm{P}}$ (sendo $\overline{\mathrm{P}}$ a média das raças paternas) não foram significativos $(\mathrm{P}>0,05) \mathrm{em}$ relação à mesma característica. Assim, pode-se afirmar que, com relação a essas duas raças, o PNT não é influenciado por diferenças genéticas maternas $\mathrm{a}_{\mathrm{A}}{ }^{\mathrm{M}}-\mathrm{a}_{\mathrm{C}}{ }^{\mathrm{M}}$ nem pela heterose direta $\left(\mathrm{h}_{\mathrm{AC}} \mathrm{I}\right)$. Igualmente, não foram significativos $(\mathrm{P}>0,05)$ para $\mathrm{PNT}$ os contrastes $3 / 4-\overline{\mathrm{P}}\left(0,5 \mathrm{~h}_{\mathrm{AC}} \mathrm{I}+1,0 \mathrm{~h}_{\mathrm{AC}}{ }^{\mathrm{M}}\right)$, $5 / 8-\overline{\mathrm{P}}\left(0,75 \mathrm{~h}_{\mathrm{AC}} \mathrm{I}+0,5 \mathrm{~h}_{\mathrm{AC}}{ }^{\mathrm{M}}\right)$ e $11 / 16-\overline{\mathrm{P}}\left(0,625 \mathrm{~h}_{\mathrm{AC}} \mathrm{I}+\right.$ $\left.0,75 \mathrm{~h}_{\mathrm{AC}} \mathrm{M}\right)$. Portanto, os efeitos conjuntos das heterozigoses direta e materna não influenciam o PNT de bezerros cruzados Canchim x Aberdeen Angus. Miquel (1986) também não encontrou efeitos heteróticos sobre o peso ao nascimento de mestiços $\mathrm{F}_{1}$ Angus x Criollo na Argentina. Por outro lado, 
Trematore et al. (1998) encontraram efeito positivo da heterozigose direta sobre o peso ao nascimento em bezerros Charolês x Nelore. Perotto et al. (1998) verificaram efeito positivo da heterose sobre o PNT nas gerações $F_{1}, 3 / 4$ e $5 / 8$ de cruzamentos Charolês x Caracu.

Na Tabela 4 são apresentadas estimativas de contrastes entre médias de grupos genéticos para P210, G210, P365 e G365. Os resultados relativos aos períodos 1990/93 e 1994/98 são consistentes em revelar a superioridade do Canchim em relação ao Aberdeen Angus com respeito a todas as características estudadas. Essa superioridade está de acordo com a composição racial do Canchim ( $5 / 8$ Charolês + 3/8 Zebu) e com a diferença entre Charolês a Aberdeen Angus em relação a crescimento e tamanho adulto (Mason 1971; Koch et al., 1989).

Os $F_{1}$ recíprocos diferiram para $\mathrm{P} 210, \mathrm{G} 210 \mathrm{e}$ $\mathrm{P} 365$. O sinal negativo das estimativas indica que a diferença $\mathrm{a}_{\mathrm{A}}{ }^{\mathrm{M}}-\mathrm{a}_{\mathrm{C}}{ }^{\mathrm{M}}$ é favorável ao Canchim, o que está de acordo com os resultados sumariados por Long (1980) para cruzamentos Charolês x Angus. Quanto a G365, o sinal do contraste foi positivo $(\mathrm{P}<0,001)$ no período 1981/88. Pode-se inferir que no presente caso, por restrições de alimentação, o ganho compensatório do grupo CA no período da desmama ao ano não foi suficiente para anular a diferença a favor do grupo AC estabelecida até a desmama.

$O$ contraste $F_{1}-\bar{P}$, que estima a heterose direta $\left(\mathrm{h}_{\mathrm{AC}} \mathrm{I}\right)$, foi positivo $(\mathrm{P}<0,001)$ com relação a $\mathrm{P} 210$. O mesmo contraste foi positivo $(\mathrm{P}<0,001)$ relativamente ao G210 no período 1981/88. Os valores de heterose aqui encontrados correspondem a $4,8 \%$ e a 4,9\% das médias das raças paternas de $\mathrm{P} 210$ e G210, respectivamente. Esses valores são comparáveis aos $4,6 \%$ e aos $6,7 \%$, para as mesmas características, encontrados por Perotto et al. (1998) para cruzamen-

TABELA 4. Contrastes entre médias de grupos genéticos para os pesos à desmama $(P 210)$ e ao ano $(P 365)$ e para os ganhos de peso médios diários do nascimento à desmama (G210) e da desmama ao ano (G365) em bovinos Canchim, Aberdeen Angus e em mestiços gerados pelo cruzamento alternado entre essas duas raças em Ponta Grossa, PR.

\begin{tabular}{|c|c|c|c|c|c|}
\hline \multirow[t]{2}{*}{ Contraste $^{1}$} & \multirow{2}{*}{$\begin{array}{l}\text { Subconjunto } \\
\text { (Período) }\end{array}$} & \multicolumn{4}{|c|}{ Característica } \\
\hline & & $\begin{array}{l}\mathrm{P} 210 \\
(\mathrm{~kg})\end{array}$ & $\begin{array}{l}\mathrm{G} 210 \\
(\mathrm{~g})\end{array}$ & $\begin{array}{l}\text { P365 } \\
\text { (kg) }\end{array}$ & $\begin{array}{c}\text { G365 } \\
\text { (g) }\end{array}$ \\
\hline \multirow[t]{4}{*}{$\mathrm{C}-\mathrm{A}$} & $1981 / 88$ & $9,8 \pm 1,5^{* * *}$ & $25 \pm 9^{* *}$ & $5,6 \pm 2,4^{*}$ & $-32 \pm 16^{*}$ \\
\hline & $1985 / 89$ & $6,0 \pm 1,0^{* * *}$ & $3 \pm 14$ & $5,5 \pm 3,4$ & $-1 \pm 21$ \\
\hline & $1990 / 93$ & $21,0 \pm 0,4^{* * *}$ & $76 \pm 4^{* * *}$ & $29,8 \pm 2,3^{* * *}$ & $56 \pm 17^{* * *}$ \\
\hline & $1994 / 98$ & $11,7 \pm 1,0^{* * * *}$ & $41 \pm 6^{* * *}$ & $31,2 \pm 1,1^{* * * *}$ & $20 \pm 9^{* * * *}$ \\
\hline \multirow[t]{2}{*}{$\mathrm{CA}-\mathrm{AC}$} & $1981 / 88$ & $-18,7 \pm 1,7^{* * * *}$ & $-97 \pm 10^{* * * *}$ & $-6,9 \pm 2,4^{* *}$ & $89 \pm 16^{* * *}$ \\
\hline & $1985 / 89$ & $-10,3 \pm 1,7^{* * *}$ & $-62 \pm 19^{* * *}$ & $-10,4 \pm 4,5^{*}$ & $1 \pm 29$ \\
\hline \multirow{2}{*}{$\mathrm{F}_{1}-\overline{\mathrm{P}}$} & $1981 / 88$ & $8,5 \pm 1,1^{* * *}$ & $40 \pm 6^{* * *}$ & $1,1 \pm 2,0$ & $-23 \pm 13$ \\
\hline & $1985 / 89$ & $6,1 \pm 1,0^{* * *}$ & $17 \pm 13$ & $1,9 \pm 3,1$ & $-28 \pm 20$ \\
\hline \multirow{2}{*}{$3 / 4-\overline{\mathrm{P}}$} & $1985 / 89$ & $8,6 \pm 0,7^{* * *}$ & $41 \pm 9^{* * *}$ & $11,8 \pm 2,4^{* * *}$ & $16 \pm 14$ \\
\hline & $\begin{array}{l}1990 / 93 \\
1985 / 89\end{array}$ & $\begin{array}{l}9,0 \pm 0,3^{* * *} \\
5,7 \pm 0,7^{* * *}\end{array}$ & $\begin{array}{l}39 \pm 3^{* * *} \\
33 \pm 9^{* * *}\end{array}$ & $\begin{array}{l}10,3 \pm 1,9^{* * * *} \\
11,2 \pm 2,4^{* * *}\end{array}$ & $\begin{array}{c}9 \pm 12 \\
32 \pm 14^{*}\end{array}$ \\
\hline \multirow[t]{2}{*}{$5 / 8-\overline{\mathrm{P}}$} & 1990/93 & $3,6 \pm 0,4^{* * *}$ & $15 \pm 4^{* * * *}$ & $9,1 \pm 2,3^{* * *}$ & $31 \pm 14^{*}$ \\
\hline & 1994/98 & $11,7 \pm 0,8^{* * *}$ & $58 \pm 5^{* * *}$ & $8,7 \pm 0,8^{* * * *}$ & $-24 \pm 7^{* * * *}$ \\
\hline $11 / 16-\overline{\mathrm{P}}$ & 1994/98 & $1,5 \pm 1.0$ & $-1 \pm 6$ & $3,4 \pm 1,1^{* * *}$ & $26 \pm 9^{* * *}$ \\
\hline$(5 / 8+11 / 16)-\overline{\mathrm{P}}$ & 1994/98 & $6,6 \pm 0,8^{* * *}$ & $28 \pm 5^{* * * *}$ & $6,2 \pm 0,8^{* * * *}$ & $0 \pm 6$ \\
\hline
\end{tabular}

${ }^{1} \mathrm{C}$ : Canchim; A: Aberdeen Angus; CA: $1 / 2 \mathrm{C}+1 / 2 \mathrm{~A} ; \mathrm{AC}: 1 / 2 \mathrm{~A}+1 / 2 \mathrm{C} ; \mathrm{F} 1:(\mathrm{CA}+\mathrm{AC}) / 2 ; \overline{\mathrm{P}}:(\mathrm{C}+\mathrm{A}) / 2 ; 3 / 4:(3 \mathrm{~A} 1 \mathrm{C}+3 \mathrm{C} 1 \mathrm{~A}) / 2$; 5/8: $(5 \mathrm{~A} 3 \mathrm{C}+5 \mathrm{C} 3 \mathrm{~A}) / 2 ; 11 / 16:(11 \mathrm{C} 5 \mathrm{~A}+11 \mathrm{~A} 5 \mathrm{C}) / 2$.

$*, * * \mathrm{e} * * *$ Significativo a $5 \%, 1 \%$ e $0,1 \%$ de probabilidade, respectivamente, pelo teste $\mathrm{t}$. 
tos Charolês x Caracu. Na revisão de Long (1980), a heterose média em cruzamentos Angus x Charolês situou-se entre $1,7 \%$ e $6,6 \%$ para o peso à desmama e entre $1,6 \%$ e $4,7 \%$ para o ganho pré-desmama. Trematore et al. (1998) verificaram valores de heterose de $8,69 \%$ e de $8,18 \%$ para peso à desmama e para ganho do nascimento à desmama, respectivamente, em cruzamentos Charolês x Nelore.

Não houve efeito da heterose direta sobre P365 nem sobre G365. Em trabalhos envolvendo as raças Angus e Charolês (Long, 1980), a heterose média para peso ao ano foi da ordem de $1,8 \%$ e para ganho da desmama ao ano, de 4,3\%. Os resultados sugerem que os grupos $\mathrm{C}$ e $\mathrm{A}$, que ganharam menos peso em comparação aos $\mathrm{F}_{1}$ até os 210 dias, tiveram melhores ganhos dos 210 aos 365 dias, de modo que não houve diferença de peso entre as médias dos puros e dos mestiços para P365.

O contraste $3 / 4-\overline{\mathrm{P}}\left(0,5 \mathrm{~h}_{\mathrm{AC}}{ }^{\mathrm{I}}+1,0 \mathrm{~h}_{\mathrm{AC}}{ }^{\mathrm{M}}\right)$ foi positivo $(\mathrm{P}<0,001)$ para $\mathrm{P} 210, \mathrm{G} 210$ e $\mathrm{P} 365$, sugerindo que há grande influência da heterozigose materna nos desempenhos até um ano de idade, o que é confirmado pelos resultados do contraste $(3 / 4-\overline{\mathrm{P}})-1 / 2(\mathrm{~F} 1-\overline{\mathrm{P}})$, que estima $\mathrm{h}_{\mathrm{AC}} \mathrm{M}$. Expressos em percentagens das médias das raças paternas, os valores estimados para este contraste representam $3,7 \%, 5,8 \%, 6,3 \%$ e $20,4 \%$ respectivamente, para P210, G210, P365 e G365. Estimativas positivas e significativas da heterozigose materna para crescimento até a desmama em bovinos de corte são encontradas na literatura (Roso, 1997; Trematore et al., 1998; Wolf et al., 1999).

A heterose estimada pelo contrate $5 / 8-\overline{\mathrm{P}}$ $\left(0,75 h_{A C}{ }^{I}+0,5 h_{A C}{ }^{M}\right)$ foi positiva para todas as características analisadas, exceto para G365, que teve sinal negativo $(\mathrm{P}<0,001)$ no período 1994/98. Esta inversão de sinais ocorreu em virtude do baixo desempenho do grupo $5 / 8 \mathrm{C}+3 / 8 \mathrm{~A}$, que nesse período não diferiu $(\mathrm{P}>0,05)$ do grupo Aberdeen Angus. Efeitos positivos da heterose em $5 / 8$ recíprocos Charolês x Caracu para pesos até a desmama são reportados por Perotto et al. (1998).

A heterose medida pelo contraste $11 / 16-\overline{\mathrm{P}}$ foi positiva $(\mathrm{P}<0,01)$ para ambos $\mathrm{P} 365$ e G365. Como o período 1994/98 envolve dados oriundos de bezerros desmamados precocemente e suplementados até os 12 meses de idade, essa heterose deve ter maior influência da heterozigose individual.
O contraste $(5 / 8+11 / 16)-\overline{\mathrm{P}}$ estima $0,687 \mathrm{~h}_{\mathrm{AC}}^{\mathrm{I}}+$ $0,625 \mathrm{~h}_{\mathrm{AC}} \mathrm{M}$, e constitui uma aproximação da estimativa da heterose retida pelo cruzamento alternado entre as duas raças, supondo-se relação linear entre heterozigose e heterose. Os resultados indicam heterose positiva para P210, G210 e P365, correspondendo, respectivamente, a 4,6\%, 5,3\% e $3,5 \%$ das médias das raças paternas para essas características.

\section{CONCLUSÕES}

1. O Canchim é superior ao Aberdeen Angus para os pesos ao nascimento, aos 210 e aos 365 dias de idade, bem como para os ganhos de peso médios diários do nascimento aos 210 dias e dos 210 aos 365 dias.

2. A heterose direta exibida pela geração $F_{1}$ Canchim x Aberdeen Angus é da ordem de 4,8\% para o peso aos 210 dias de idade e de $4,9 \%$ para o ganho de peso médio diário do nascimento aos 210 dias de idade.

3. A heterose materna exibida pelos $3 / 4$ Canchim x Aberdeen Angus recíprocos é da ordem de $3,7 \%$ para o peso aos 210 dias de idade, $5,8 \%$ para o ganho de peso médio diário do nascimento aos 210 dias de idade, 6,3\% para o peso aos 365 dias de idade e $20,4 \%$ para o ganho de peso médio diário do 210 aos 365 dias de idade.

4. O efeito genético materno do Canchim supera o do Aberdeen Angus em 9,1\% para o peso aos 210 dias, em 5,1\% para o peso aos 365 dias e em 13,9\% para o ganho de peso médio diário do nascimento aos 210 dias de idade.

5. Os níveis de heterose total exibidos pela média das terceira e quarta gerações avançadas do cruzamento alternado entre Canchim e Aberdeen Angus são da ordem de 4,6\% para o peso aos 210 dias, 5,3\% para o ganho de peso médio diário do nascimento aos 210 dias e de $3,5 \%$ para o peso aos 365 dias de idade.

\section{REFERENCIAS}

ALENCAR, M.M.; COSTA, J.L.; CORRÊA, L.A. Desempenho produtivo de fêmeas das raças Canchim e Nelore. I. Desenvolvimento e puberdade. Pesquisa 
Agropecuária Brasileira, Brasília, v.22, n.7, p.753-758, jul. 1987.

ALENCAR, M.M.; TREMATORE, R.L.; OLIVEIRA, J.A.L.; ALMEIDA, M.A. Características de crescimento até a desmama de bovinos da raça Nelore e cruzados Charolês - Nelore. Revista Brasileira de Zootecnia, Viçosa, v.27, n.1, p.40-46, 1998.

ALVES FILHO, C.D.; RESTLE, J. Efeito do grupo genético no peso ao nascimento e ao desmame de terneiros de corte. In: REUNIÃO ANUAL DA SOCIEDADE BRASILEIRA DE ZOOTECNIA, 34., 1997, Juiz de Fora. Anais. Juiz de Fora : Sociedade Brasileira de Zootecnia, 1997. v.3, p.202-204.

BARBOSA, P.F.; ALENCAR, M.M. Sistema de cruzamentos em bovinos de corte: estado da arte e necessidades de pesquisa. In: REUNIÃO ANUAL DA SOCIEDADE BRASILEIRA DE ZOOTECNIA, 32., 1995, Brasília. Anais. Brasília : Sociedade Brasileira de Zootecnia, 1995. p.681-683.

BARBOSA, P.F; DUARTE, F.A.M. Crossbreeding and new beef cattle breeds in Brazil. Revista Brasileira de Genética, Ribeirão Preto, v.12, n.3, p.257-301, 1989. Suplemento.

BECKER, A.S. Pesquisas mostram quais os melhores cruzamentos. A Granja, Porto Alegre, n.449, p.16-23, 1985.

CHAPMAN, H.D.; CLYBURN, T.M.; McCORMICK, W.C. Angus, Polled Hereford, and Santa Gertrudis in two- and three-breed rotational crossbreeding programs. In: KOGER, M.; CUNHA, T.J.; WARNICK, A.C. (Ed.). Crossbreeding beef cattle. Gainesville : University of Florida Press, 1973. p.459. (Series, 2).

EUCLIDES FILHO, K.; FIGUEIREDO, G.R.; SILVA, L.O.C. da; ALVES, R.G. de O.; CAMILO, I.B. Pesos ao nascer e à desmama e ganho pré-desmama de Nelore e seus mestiços com Fleckvieh, Chianina, Charolês e Angus. In: REUNIÃO ANUAL DA SOCIEDADE BRASILEIRA DE ZOOTECNIA, 33., 1996, Fortaleza. Anais. Fortaleza : Sociedade Brasileira de Zootecnia, 1996. v.1, p.164-166.

KOCH, R.M.; CUNDIFF, L.V.; GREGORY, K.E. Beef cattle breed resource utilization. Revista Brasileira de Genética, Ribeirão Preto, v.12, n.3, p.55-80, 1989. Suplemento.
LONG, C.R. Crossbreeding for beef production: experimental results. Journal of Animal Science, Champaign, v.51, n.5, p.1197-1223, 1980.

MAACK, R. Geografia Física do Paraná. Curitiba : M. Roesner, 1968. 350p.

MASON, I.L. Comparative beef performance of the large cattle breeds of Western Europe. Animal Breeding Abstract, Wallingford, v.39, n.1, p.1-29, 1971.

MIQUEL, M.C. Heterosis and breed transmitted and maternal effects in growth traits to weaning in Angus, Criollo and reciprocal cross calves. In: WORLD CONGRESS ON GENETICS APPLIED TO LIVESTOCK PRODUCTION, 3., 1986, Lincoln. Proceedings. Lincoln : University of Nebraska, 1986. v.9, p.342-346.

PEROTTO, D.; ABRAHÃO, J.J.S.; CUBAS, A.C. Efeitos da raça e da heterozigose sobre características ponderais de bezerros Nelore e mestiços Red Angus x Nelore. Revista Brasileira de Zootecnia, Viçosa, v.28, n.3, p.504-511, 1999.

PEROTTO, D.; CUBAS, A.C.; ABRAHÃO, J.J.S.; MELLA, S.A.; JOSÉ, W.P.K. Desempenho ponderal de animais Nelore e cruzas com Nelore. I. Período pré-desmama. In: REUNIÃO ANUAL DA SOCIEDADE BRASILEIRA DE ZOOTECNIA, 33., 1996, Fortaleza. Anais. Fortaleza : Sociedade Brasileira de Zootecnia, 1996. v.1, p.124-126.

PEROTTO, D.; CUBAS, A.C.; MOLETTA, J.L.; LESSKIU, C. Pesos ao nascimento e à desmama e ganho de peso do nascimento à desmama em bovinos das raças Charolesa e Caracu e em mestiços gerados pelo cruzamento alternado Charolês x Caracu. Revista Brasileira de Zootecnia, Viçosa, v.27, n.4, p.730-737, 1998.

POSTIGLIONI, S.R.; PICANÇO, R.G.C. Avaliação, sob pastejo, de três gramíneas tropicais e do campo nativo, na região dos Campos Gerais do Paraná. Pesquisa Agropecuária Brasileira, Brasília, v.14, n.1, p.53-61, mar. 1979.

RAZOOK, A.G.; LEME, P.R.; PACKER, I.U.; LUCHIARI FILHO, A.; NARDON, R.F.; TROVO, J.B.; CAPELOZZA, C.N.Z.; PIRES, F.L.; NASCIMENTO, J.; BARBOSA, C.; COUTINHO, J.L.B.; OLIVEIRA, W.J. Evaluation of Nelore, Canchim, Santa Gertrudis, Holstein, Brown Swiss and Caracu 
as sire breeds in matings with Nelore cows: effects on progeny growth, carcass traits and crossbred productivity. In: WORLD CONGRESS ON GENETICS APPLIED TO LIVESTOCK PRODUCTION, 3., 1986, Lincoln. Proceedings. Lincoln : University of Nebraska, 1986. v.11, p.348-351.

ROSO, V.M. Heteroses materna e individual sobre o ganho de peso do nascimento ao desmame em bovinos Angus x Nelore. In: REUNIÃO ANUAL DA SOCIEDADE BRASILEIRA DE ZOOTECNIA, 34., 1997, Juiz de Fora. Anais. Juiz de Fora : Sociedade Brasileira de Zootecnia, 1997. v.3, p.139-141.
SAS INSTITUTE (Cary, Estados Unidos). SAS/STAT user's guide: version 6. 4.ed. Cary, 1994. v.2.

TREMATORE, R.L.; ALENCAR, M.M.; BARBOSA, P.F.; OLIVEIRA, J.A.L.; ALMEIDA, M.A. Estimativas de efeitos aditivos e heteróticos para características de crescimento pré-desmama em bovinos Charolês-Nelore. Revista Brasileira de Zootecnia, Viçosa, v.27, n.1, p.87-94, 1998.

WOLF, P.G.L.; GREGORY, R.M.; MATTOS, R.C.; BRITO, F.B. Heterozigose individual e materna sobre o ganho de peso do nascimento ao desmame de terneiros Pampiano-Braford. Ciência Rural, Santa Maria, v.29, n.3, p.533-537, 1999. 